\title{
A TERRA PLANA É AQUI
}

\author{
The Flat Earth Is Here
}

\author{
Roberto BEZERRA \\ Universidade Federal do Rio de Janeiro \\ robertobezerra@letras.ufrj.br \\ https://orcid.org/0000-0002-6570-2244
}

A cena na tela do computador é caricatural, mas existe: ao fundo a vista do oceano filmado de uma praia, enquanto em primeiro plano uma mão cuidadosa segura entre dois dedos a régua de plástico tentando deixá-la paralela à linha do horizonte. Até que, triunfal, a voz da mão sem rosto anuncia: - Totalmente plana, nada de curvatura. E ali, naquele instante, a teoria da Terra Bola cai por terra.

Só pode ser brincadeira, penso. Ocorre que entre observações empíricas, experimentos pseudocientíficos, fóruns de debate, modelos computacionais, revelações bíblicas, documentários, reportagens e sítios na internet, seja em defesa da Terra Biscoito ou contra ela, uma busca por "terra plana" no Google resultará em 1.030.000 caminhos. Se preferir "flat earth", 7.210.000 resultados; ou, se quiser menos horas de investigação, "terre plate" lhe dará apenas 678.000 possibilidades. Outro número, este de uma pesquisa do Instituto Datafolha de julho de $2019^{1}$, estima que $7 \%$ da população brasileira, ou seja, aproximadamente 11.000.000 de pessoas acreditam que a Terra é plana. Não são números de brincadeira. Principalmente porque a crença na terra plana é só um sintoma de um fenômeno maior e bastante popular no Brasil: a onda de negacionismo científico, a qual gosto de chamar carinhosa e metonimicamente de terraplanismo, que se espraia por diferentes áreas do conhecimento. Onda que pode ser um tsunami mortal, como atestam os números trágicos da pandemia do COVID-19 entre nós.

Tais números, tanto de crentes quanto de mortos, dão uma certa visão da extensão territorial da Terra Disco, que já ocupa uma área de milhões de quilômetros quadrados em oceanos conspiratórios, montanhas e vales de constatações empírico-sensoriais, além de

\footnotetext{
1 Disponível em: <https://www1.folha.uol.com.br/ciencia/2019/07/7-dos-brasileiros-afirmam-que-terra-eplana-mostra-pesquisa.shtml> . Acesso em: 11 jul. 2020.
} 
vastos desertos de (até boa) fé. Que ninguém se engane: a Terra Plana existe e está no meio de nós, ainda que seja como presença síncrona inapreensível de alguma dimensão do multiverso. A despeito de nossa vontade ou de sua validade científica, o mapa da Terra Plana é parte de nossa geografia, o que autoriza, convida ou mesmo clama por expedições exploratórias. O que proponho aqui é uma breve incursão nesse território.

Se aprendemos algo com a milenar história colonial ocidental, é que toda incursão em território alheio carrega em si a semente da barbárie, da humilhação e desumanização do outro. Tenho plena consciência de que a maneira como icei as velas de minha nau aos ventos deste texto até agora reverbera mais uma vez o velho projeto colonial: a pretensa superioridade, a crença inequívoca e pedante na infalibilidade da ciência, a ironia, a desvalorização da experiência e da fé. Essas coisas estão ali, eu sei, assim como estiveram em tantas naus-macho brancas aportadas nos territórios invadidos dos novos mundos. Por isso vou tentar me policiar de agora em diante e buscar me despir da soberba e da postura do civilizado que deseja resgatar o aborígene de sua ignorância. Se quero de fato dialogar com habitantes da Terra Plana, vou ter de produzir as condições para isso, encontrar a translinguagem que possa fundar nosso território (in)comum. Houve um tempo em que simplesmente aspirávamos à "tolerância" e desejávamos que cada pessoa vivesse suas verdades no exercício de sua liberdade individual. Essa ilusão é morta. A Terra Plana não está lá, em oposição à Terra Bola aqui. Tudo o que temos é o espaço multidimensional e síncrono do complexo Terra Bola/Plana em que vivemos. O diálogo não é uma opção, ele vai acontecer, está acontecendo, ainda que se manifeste frequentemente nas fronteiras de sua própria dissolução, como silenciamento e barbárie. Só nos cabe buscar interferir eticamente, creio eu, nos termos e rumos dessa negociação.

Imagino minha primeira parada no novo mundo como um encontro com o corpo todo da mão que segurava a régua sobre a linha do horizonte. E é importante que seja assim, carne a carne, corpo a corpo, para de alguma maneira diminuir as distâncias e castrar as mediações que se interpõem em nossa comunicação quando nos apresentamos como avatares, perfis de usuário, operadores de smartphones, membros de comunidades virtuais ou inquilinos de algum endereço de I.P. - toda essa parafernália gamificadora que não oferece resistência ao embrutecimento, à reificação e à violência. Considero o afeto e a presença, a consciência recíproca da presença dos corpos vivos, como ponto de partida 
para que o diálogo prospere.

Admito que é legítimo questionar essa condição como pré-requisito para o diálogo. Chega a ser utópico imaginar que em 2020, sob os efeitos traumáticos de uma pandemia mundial, alguém possa advogar em favor da presença como experiência necessária para o diálogo. Mas insisto que este seja o paradigma. Por isso, imagino minha primeira parada no novo mundo como um encontro com o corpo todo da mão que segurava a régua, assim, carne a carne, corpo a corpo, mesmo quando o que tenho diante de mim sejam sinais luminosos, pixels, memes, símbolos gráficos ou outras formas digitais plurimodais. E é importante que seja assim para que a conexão se estabeleça sob o pressuposto vigilante da consciência crítica acerca da interferência dessas mediações e dos sentidos que elas produzem e a que induzem. (Abro este parêntese para uma ressalva que não vou poder desenvolver neste texto: o fato de que concebo esse ato de fazer emergir a presença humana na outra ponta, a despeito do meio digital, não como uma mera produção de imagens mentais. Concebo-o como ação, como produção de linguagem, translinguagem, a qual precisa desafiar as convenções e valores embutidos nos gêneros de suporte digital, a fim de produzir outras formas de dizer, transgressoras aos limites e sentidos dados pelos emojis, pelo internetês, pelas caixas de diálogo, os cento e quarenta caracteres possíveis do Twitter, ou as cinco carinhas do Facebook, mais o dedão de joinha, que pretendem representar o espectro das emoções que podemos manifestar diante de uma postagem. Concebo-o como um esforço de apropriação crítica dessa linguagem de forma a continuamente desmaquinizá-la, para então restabelecer a conexão e afirmar a existência de pessoas, não robôs, como sujeitos do discurso.)

Retomando: dada aquela condição, a consciência mútua da copresença dos corpos vivos, mesmo que a distância, há esperança de que o diálogo prospere. $\mathrm{O}$ afeto da presença é condição necessária para a escuta, entendida como disponibilidade para o diálogo fundada no engajamento ético, que pressupõe atenção acolhedora e responsabilidade também pelo outro, cuja presença reconheço simultaneamente como diferença e semelhança, como opacidade e espelhamento. Dada essa condição, todo desejo de aniquilação, toda manifestação de violência dirigida ao não-eu torna-se autodestrutiva, ao passo que o trabalho de escuta atua como força contrária ao silenciamento, como resistência à barbárie. E como nos lembra Sharon Todd, a escuta como "resposta não 
violenta" não é uma atitude altruísta e tolerante que se estabelece apesar da diferença; pelo contrário, ela é constitutiva e intrínseca à diferença, sem a qual estou fadado a "ouvir as palavras de outros apenas para confirmar o que sei (ou creio saber)" (2003, p. 136). Proponho furar a Terra Bolha, caminhar pela Terra Plana, afirmar e reconhecer presenças, escutar.

Em nosso encontro, estendo a mão à mão que agora solta a régua para apertar a minha. As primeiras palavras que escuto da boca do corpo da mão que segurava a régua, sussurradas, me dizem que a experiência da régua alinhada ao horizonte é boa, é sã. Sã porque está fundada numa observação lógico-empírica que parece, portanto, é, irrefutável: aos olhos, a linha do horizonte imita a geometria plana da régua, donde, a Terra é plana. Concordo. É sã porque permite ao meu interlocutor participar ativamente de um processo de compreensão do mundo do qual ele se sente alheio, alienado. Ele me conta que já se deparou com tantos argumentos em favor da redondeza do planeta mas, depois de um breve momento de confiança, eles se tornavam fugidios, abstratos demais, hostis, ininteligíveis, sempre relacionais, quando não relativistas, complexos, impalpáveis e distantes, de forma que quando dava por si, não estava mais ali. Exigiam dele fé numa ciência excludente, inatingível, elitista; condicionavam sua permanência no território do conhecimento a uma posição subalterna, como serviçal cujo trabalho era organizar a prataria e os apetrechos do jantar naquela ordem pré-determinada pelos patrões, sem que o convite para sentar à mesa em algum momento surgisse.

Escuto, patrão de casa grande que sou. Sinto-me um tanto envergonhado, ainda que não me sinta diretamente culpado. Faz diferença? E enquanto escuto, penso que daqui a pouco terei de pôr à mesa meus argumentos. Questiono o que poderei fazer para renovar o ritual, a comida, a conversa e o pertencimento. Sinto sobre meus ombros a responsabilidade pelo diálogo: se algo puder ser transformado, se alguma forma construtiva de ressignificação puder se instaurar, creio que dependerá mais de minhas ações, justamente pelos privilégios que recebo como membro honorário do country club acadêmico. Ironicamente, sinto-me discursivamente inseguro para reafirmar em outra linguagem o legado da ciência que comungo; logo eu, letrado na geometria dos mundos esféricos.

A conversa se estende e quanto mais se estende, mais amistosa fica. Não vamos 
hoje à sala de jantar e a seus cristais. Ficamos na varanda com os pratos na mão, depois de termos cozinhado juntos - alguns quitutes de minha especialidade entraram no cardápio. Ali no quintal uma fogueira ilumina a noite e assa algumas batatas-doces. E quando chega a hora de servir, como previa, estou desajeitado: gaguejo, refaço a todo instante o que disse, insatisfeito, tentando lidar com ferramentas que não sei manusear; derrubo molho em sua roupa. Descubro que não disponho de uma narrativa tão sintética e imagética quanto a fábula da régua no horizonte (esta é uma grande vantagem do terraplanismo sobre o conhecimento formal, a possibilidade de se traduzir numa profusão de "mitemas" cotidianos). Tento contar histórias - Ptolomeu, Copérnico, Galileu; falo de tecnologias supertelescópios, satélites, sistemas de posicionamento global; evito modelos matemáticos e conceitos que não consigo explicar nem para mim mesmo. Tento entrecruzar nossas falas; tento não deixar de ouvir enquanto falo e não deixar de dizer enquanto escuto.

Quando enfim nos despedimos com um sorriso, nenhum de nós tem coragem de perguntar: - No final das contas, a Terra é plana ou redonda? De minha parte, minhas convicções objetivas sobre a esfericidade do planeta continuam inalteradas e devo confessar que em nenhum momento da viagem imaginei que pudessem ser abaladas. (Isto quer dizer que estou preso a uma concepção cristalizada, uma narrativa imutável sobre o fato e, assim sendo, sou tão obtuso e anticientífico quanto um terraplanista irredutível? Não, não quer dizer isso, pois o modelo Terra Bola não é alvo de questionamentos ou de desvelamento de suas contradições internas na mesma medida que o outro modelo.) Mas admito que a confiança adquirida pela força da história e pelo respaldo de minha comunidade de prática, a academia, é um obstáculo a ser transposto na busca pelo diálogo e na disposição para a escuta. Por outro lado, se para mim a Terra continua bola, minha compreensão e representação do terraplanismo são ressignificadas em função da experiência de incursão, presença e escuta.

Tento, sem sucesso, extrair da expressão de Aldecir alguma pista de que tenha sido convencido por meus argumentos. Quero crer que ao menos uma semente de dúvida tenha sido plantada. No caminho de volta, tenho mais perguntas que respostas, mais hipóteses que asserções. Porque mesmo que meus argumentos sejam sólidos, há um conjunto de valores e sentidos próprios ao negacionismo que a ciência não alcança. Penso sobre o bem-estar, segurança e senso de pertencimento que o terraplanismo articula ao configurar 
comunidades de prática em torno de suas verdades e crenças. Penso no poder estabilizador e no potencial para apaziguamento dos conflitos internos que "teorias" terraplanistas têm quando defendem e reafirmam tradições, valores religiosos e morais ameaçados pelo incessante ceticismo, questionamento e fragmentação próprios da prática científica e das teorias contemporâneas. Penso na absorção rápida, na velocidade da transmissão, na capilaridade e horizontalidade de saberes que parecem agora poder fluir democraticamente entre todos nas redes sociais, não mais enclausurados nos feudos universitários. Penso na satisfação de agora poderem se vingar, de poderem ostentar seu conhecimento em detrimento do conhecimento do outro, de poderem refutar, comprovar, ridicularizar, "mitar", dar o troco àqueles que se achavam superiores, cultos e donos do saber. Penso na recompensa do reconhecimento de si, na afirmação identitária inerente ao mutirão que se vai formando para a defesa de "nós" contra "eles" - os doutrinadores, os eruditos, os ateus, os imorais, os inimigos, os comunistas, os infiéis, os romanos. Penso no terraplanismo como um sistema, um maquinário de vários tentáculos (epistemológico, cultural, político, ideológico, identitário) que se apresenta para restaurar a ordem e o poder de um ethos conservador, cristão e individualista que se percebe (ou se representa) sob ameaça de extinção.

Se de fato a aceitação de certos discursos negacionistas e teorias conspiratórias carrega valores e sentidos que excedem a racionalidade interna e a validade de suas enfabulações, isto significa que o diálogo e a busca por entendimento precisam alcançar essa dimensão excedente e considerar as motivações e implicações que sustentam a adesão a tais crenças ou narrativas, visto que simplesmente contrapor a densidade histórica, lógica e experimental do conhecimento acumulado ao negacionismo será uma resposta apenas parcial ao problema. Em certos casos, essa disputa pelo valor de verdade (ainda que transitório) de um conjunto de conhecimentos pode ser até mesmo uma questão secundária. Afinal, que diferença faz, objetivamente, para o dia-a-dia da grande maioria dos terráqueos se a Terra é plana ou arredondada? Nesse sentido, imagino que o engajamento de Aldecir com o tema possa admitir a incerteza, a desconfiança ou mesmo a possibilidade de a Terra ser um globo. Imagino até que ele possa intimamente admitir que está errado e mesmo assim optar pela versão fantasiosa. O alinhamento com a posição terraplanista pode não estar fundado no valor de verdade da formulação, mas pode se 
justificar por aquele conjunto de outros valores, sentidos e implicações que dialogam de forma mais orgânica e irracional com seus anseios e necessidades.

O segredo de Aldecir persiste. Não sei se fui capaz de comunicar minha posição. Não sei se, comunicada, minha proposição foi aceita ou considerada. Não sei se o valor de verdade que atribuo a ela foi traduzido em valor equivalente para meu interlocutor. Nem sei se esse valor era o ponto fundamental de nosso encontro. Porém, retorno à questão do corpo-presença-escuta para mais uma vez reafirmar sua importância, pois, se inverto os sinais e me coloco como o "outro" do diálogo, posso confiar que a escuta tenha estimulado resistência à violência contra mim e ao meu silenciamento; que tenha operado para produzir algum nível de desconstrução de minha representação estereotipada como inimigo, ameaça, como dono do saber, doutrinador, imoral, comunista, infiel, romano. A presença e a escuta bem podem ter influído sobre aquela gama de valores excedentes tão difusos quanto imbricados nos sentidos do terraplanismo.

Abandono aqui a narrativa semificcional sobre minha viagem de colonização à Planamérica e a tentativa talvez frustrada de converter um nativo ao terrabolismo. Creio que cumpriu seu propósito. A personagem Aldecir é uma espécie de proto-terraplanista, um tipo que concentra características abrangentes e esquemáticas deste grupo. É também uma representação idealizada e um tanto rousseauniana guiada pelo desejo de gerar esperança e empatia. $\mathrm{O}$ que não quer dizer que não seja real. Mas é também uma personagem, apenas uma entre tantas nada ficcionais que encontramos por aí.

Um exemplo bastante concreto e emblemático para negar e afirmar a caracterização de Aldecir é Olavo de Carvalho. O astrósofo da Virgínia, em vídeos que retirou de seu canal, mas que ainda podem ser encontrados em canais de pessoas que insistem em nos lembrar do episódio, disse outrora, sorrateiramente, que nutria questionamentos e dúvidas sobre o "problema" da Terra Plana. Sugeriu que, mesmo alguém de inteligência aguda e privilegiada como a sua, não seria capaz de refutar contundentemente a experimentação e a razoabilidade da "teoria" da Terra Plana. Afirmou ainda que "teorias certas podem ter mil argumentos falsos e teorias falsas podem ter mil argumentos verdadeiros" ${ }^{\prime 2}$. Assim, despretensiosamente, entre considerações filosóficas e acusações à incompetência e/ou objetivos espúrios de instituições estabelecidas, foi

\footnotetext{
${ }^{2}$ Exemplo extraído de: <https://www.youtube.com/watch?v=u2HIuOxZIUs\&list=WL\&index=11 >. Acesso em: 12 set. 2020.
} 
borrifando sua fumaça obscurantista sobre milhares de anos de história da matemática, da astronomia e da física. Olavo tem lá sua astúcia, advoga para si um lugar de destaque no panteão do pensamento ocidental contemporâneo; por isso, sabe que não pode simplesmente segurar a régua sobre a linha do horizonte. Seu terraplanismo tem método e, principalmente, tem um projeto político-ideológico claro. De minha parte, prefiro a simplicidade e a candura de Aldecir.

Entre Aldecir e Olavo há uma miríade de terraplanistas dos mais variados tipos e graus, inspirados pelas mais variadas causas: youtubers, jornalistas, comentaristas políticos, celebridades, parentes em festas de família, profissionais liberais, liberais, ministros, líderes religiosos, taxistas, ambulantes etc. Entre eles prosperam as investigações sobre e contra o Foro de São Paulo, a Ideologia de Gênero ou o Marxismo Cultural, a favor do movimento antivacina ou por uma nova história do período militar. Terraplanistas e terraplanismos são múltiplos, complexos e podem ser contraditórios entre si, mas convergem em algumas características básicas: libertam seus seguidores da opressão de discursos hegemônicos estabelecidos em diversas áreas; constituem-se como vanguardistas ou revolucionários; permitem a filtragem e ratificação do novo conhecimento pela experiência empírica individual (o novo conhecimento pode ser vivido, verificado, compreendido e compartilhado também enquanto experiência subjetiva). São negacionistas, não no sentido de negarem o método científico, mas no sentido de negarem a suposta apropriação de discursos científicos por ideologias de esquerda. O terraplanismo, na verdade, celebra o modus operandi da ciência: tanto a régua de Aldecir quanto o cachimbo e a bibliografia de Olavo emulam formas do agir científico.

Manifestações tão diversas e disseminadas de terraplanismo são hoje um desafio concreto tanto às instituições de cultura, pesquisa e ensino da Terra Bola, como à razoabilidade e sanidade dos discursos públicos que sustentam uma ideia de democracia, ainda que frágil. As formas inevitáveis de diálogo e choque que ocorrem nesses espaços contestados clamam por estratégias contingentes à especificidade de cada momento. Quando evoquei a imagem da presença e escuta em minha história com Aldecir, o fiz pensando no cidadão ou cidadã mais vulnerável, mais alheio e carente de participação em tais discursos, mais suscetível à ação de influenciadores, líderes e formadores de opinião. Já diante de agentes investidos de poder, na mídia, em cargos públicos ou patrocinados por 
entidades particulares, agentes comprometidos com o projeto antidemocrático em curso no Brasil, há que se buscar também a confrontação veemente de ideias e teorias, o desmascaramento e desconstrução de teorias conspiratórias, há que se concorrer pela ocupação do espaço público e há que se levantar contra o alastramento do obscurantismo. Afeto, empatia e escuta em nada se opõem à responsabilidade e à luta por justiça. Pelo contrário.

\section{REFERÊNCIAS}

TODD, S. Listening as an attentiveness to 'dense plots'. In:

Learning from the other: Levinas, psychoanalysis, and ethical possibilities in education. Albany: State University of New York Press, 2003, p. 117-139. 